\title{
Johanneische Gedanken vor dem Isenheimer Altar
}

Pierre Bühler

Wieder einmal stehe ich im Museum Unterlinden in Colmar, vor dem Isenheimer Altar von Matthias Grünewald, genauer: vor seiner Kreuzigungsszene (vgl. das Bild in der Mitte des vorliegenden Heftes). Was mir heute stärker auffällt als andere Male ist die johanneische Prägung des Gemäldes (vielleicht weil mir noch gewisse Auseinandersetzungen des vergangenen Semesters zur johanneischen Kreuzestheologie lebhaft in Erinnerung sind).

\section{Eine johanneische Kreuzigung?}

Freilich ist auch einiges im Bild, das ohne jegliche johanneische Spezifizität ist, das soll nicht geleugnet werden. Auffallend ist aber, wie die Mutter Jesu und der Lieblingsjünger miteinander beim Kreuz stehen (vgl.Joh 19, 25-27). Eigentlich müssten drei Frauen zu sehen sein. Dass neben der Mutter Jesu nur Maria von Magdala aufs Bild kommt, am Kreuz kniend, könnte damit zu tun haben, dass sie bei Johannes dann als erste am Ostermorgen vor der leeren Gruft steht (Joh 20, 1). Auf jeden Fall hat sie anscheinend bereits ihren Balsamtopf zum Einbalsamieren des Leichnams bei sich. Das könnte zwar eher ein synoptisches Motiv sein (vgl. Mk 16,1), doch auch in Joh 12, 7 geht es um das Aufbewahren von Balsam für den Tag des Begräbnisses (vgl. Mk 14, 8 par.; siehe aber auch Joh 19,39).

Da ist nun aber auch das Lamm Gottes von Joh 1, 29, etwas naiv, ja fast kitschig dargestellt, ein Kreuz tragend, das das Kreuz Christi redupliziert, und sein Blut verlierend, das in einen bereitstehenden Kelch fliesst.Vor allem aber ist auf der rechten Seite des Bildes, zusammen mit dem Lamm, ein sehr johanneischer Johannes der Täufer zu sehen. Er wird als Hermeneut dargestellt: In der einen Hand hält er die heilige Schrift und mit dem Finger der anderen Hand weist er auf den hin, der diese Schrift soeben erfüllt (vgl. Joh 19, 24.28.36). Unterstützt wird hier die Zeugenfunktion des Täufers mit einem johanneischen Zitat: Illum oportet crescere, me autem minui; "Jener muss wachsen, ich aber abnehmen" (Joh 3, 30).

Offenbart dieses johanneisch geprägte Bild auch etwas von den Spannungen der johanneischen Kreuzestheologie? Darüber lässt sich streiten, und währenddem ich das Bild betrachte, rollen die möglichen Argumente ab... 


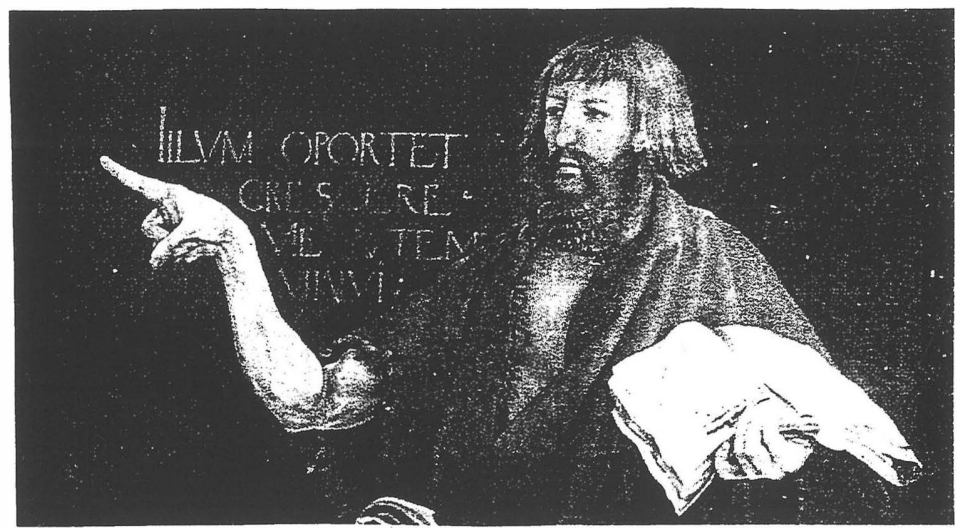

\section{Ein Gerichtsbild?}

In vielem ist Grünewalds Gemälde ein Gerichtsbild, geprägt von Leidensgebärden. Das zeigt sich etwa an den Händen, an den zwar gefalteten, aber dennoch sich windenden Händen der Maria von Magdala, die den vom Leiden gespreizten Fingern des Gekreuzigten selbst korrespondieren. Doch auch die Hände der Mutter sind dem Kreuz leidend entgegengestreckt. Leiden kommt auch im geneigten Haupt Christi zum Ausdruck (vgl. Joh 19, 30).

Doch auch der ganze Leib des Gekreuzigten ist «hingerichtet». Um das noch zu verschärfen, versetzt Grünewald den Gekreuzigten in seine Zeit hinein, die tiefsten Ängste des Spätmittelalters aufnehmend: Es wird hier ein pestkranker Gekreuzigter dargestellt, dessen fast etwas grünlicher Leib voll von Pestbeulen ist.

Also ein Tod, der das Gericht zum Ausdruck bringt, der dieses Gericht auch vollzieht ("Es ist vollbracht», Joh 19, 30)? Ein Gericht, das Kehrseite der Gnade ist, die sich im fleischgewordenen Wort angeboten hatte? Gericht als Antwort auf eine Welt, die diese angebotene Gnade des Fleischgewordenen abgelehnt hat?

\section{Der Gekreuzigte als Fleischgewordener?}

Aber stehen sich denn im Johannesevanglium die Fleischwerdung und die Kreuzigung so unvereinbar gegenüber? Als Pestkranker, wie ihn Grünewald darstellt, ist der Gekreuzigte gerade ganz sichtbar, ganz plastisch Fleisch geworden. Fleisch in aller Dichte, in aller Undurchsichtigkeit, Fleisch in krasser Konkretion hängt hier am Kreuz. Ist die Fleischwerdung, wenn sie nicht bis zu dieser Fleischwerdung geht, 


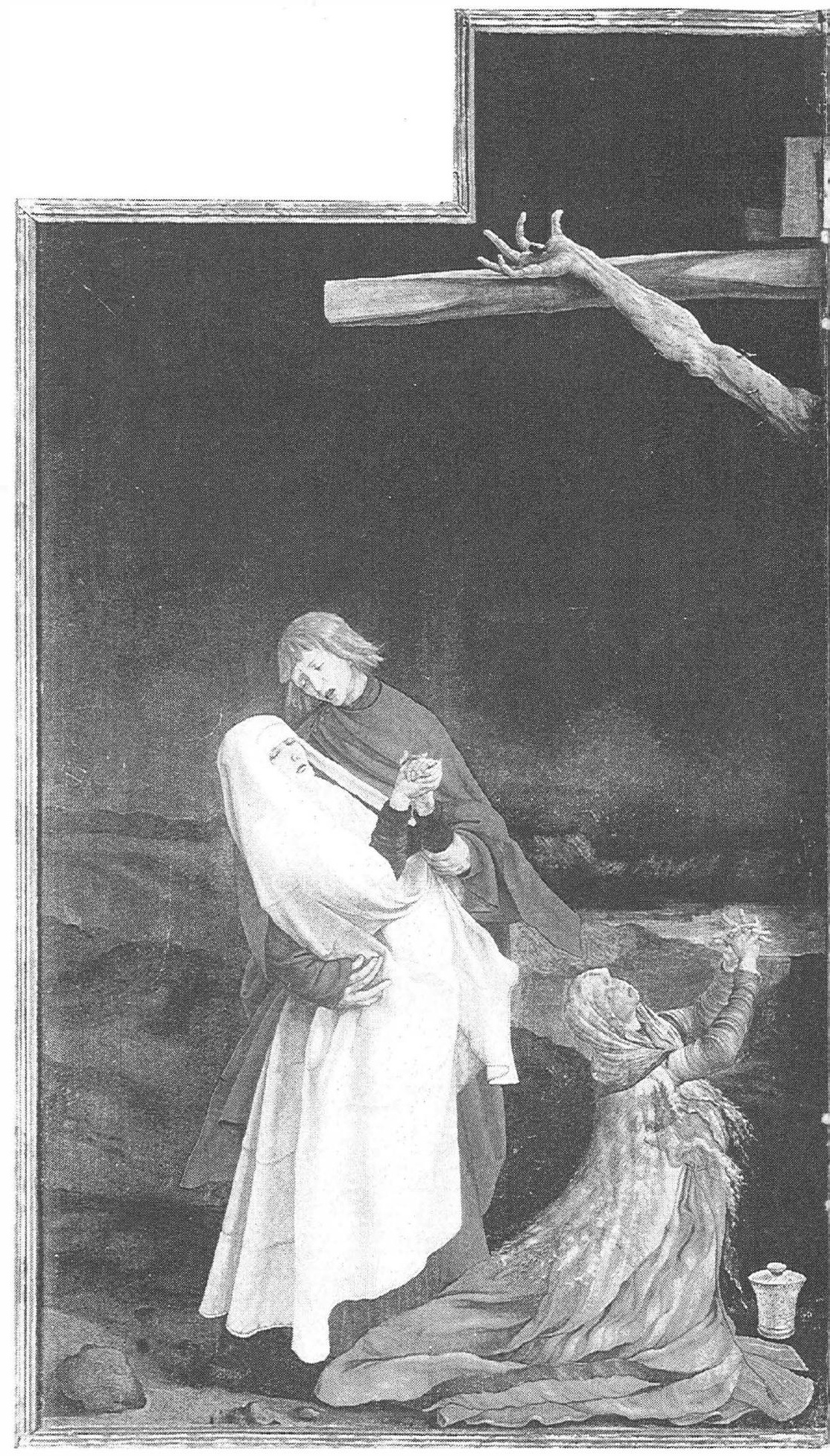


wirklich eine Fleischwerdung? In diesem Sinne wäre die Kreuzigung gerade die Vollendung der Fleischwerdung, und das Wort «Es ist vollbracht» nicht zuerst ein Gerichtswort, sondern, gerade als Wort des voll und ganz fleischgewordenen Wortes, ein Vollendungswort, ein Heilswort.

Aber dann müsste in dieser johanneisch geprägten Kreuzigungsszene auch etwas von der damit verheissenen Gnade zum Ausdruck kommen? Wo geschieht das, wenn wir nicht beim etwas kitschigen Lamm bleiben wollen, mit dem in den Kelch fliessenden Blut?

\section{Ein gewichtiger Gekreuzigter}

Im Johannesevangelium wird die Kreuzigung immer als Erhöhung und als Verherrlichung zur Sprache gebracht. Interessanterweise wird auch dieser Aspekt bei Grünewald sehr plastisch gestaltet. Wenn der Täufer sagt: Illum oportet crescere, so kann man von diesem gekreuzigten Christus sagen, dass er tatsächlich gewachsen ist, dass er, im Vergleich zu den anderen Gestalten des Bildes, zu einem Riesen herangewachsen ist! Der Gekreuzigte als hängender Riese: Könnte das so etwas wie Erhöhung im johanneischen Sinne darstellen?

Hinzu kommt dann auch, dass dieser riesenhafte Gekreuzigte schwer ist. Die Schwere liegt im ganzen Leichnam, zieht auf die Hände und die Arme, und selbst der Querbalken des Kreuzes scheint sich unter dem Gewicht zu biegen.

Alles in allem also ein gewichtiger Gekreuzigter. 'Gewichtig) im Sinne von sschwer, aber dabei vielleicht auch (gewichtig) im Sinne von 'wichtig), sbedeutend). Also ein herrlicher Gekreuzigter, wenn man sich daran erinnert, dass die Herrlichkeit im hebräischen kavod auch diesen Aspekt des Gewichts mit beinhaltet. Damit wäre die johanneische Verherrlichung ausgedrückt: Interessanterweise, als Gewicht, nicht im Gegensatz zur Fleischlichkeit, sondern gerade in engster Verbindung mit ihr. Gerade als am Kreuz hängendes Fleisch ist Christus gewichtig.

Käme damit in der Kreuzigungsszene das zur Sprache, was im Prolog betont wurde: «Und das Wort ward Fleisch und wohnte unter uns, und wir schauten seine Herrlichkeit [...]" (Joh 1, 14)? Dass die Herrlichkeit im Fleischgewordenen geschaut werden kann, bekäme somit in Grünewalds "gewichtigem» Christus plastische Gestalt.

Das hiesse nun aber auch, dass sich im Johannesevangelium Gericht und Gnade nicht auf verschiedene Phasen der Erzählung verteilen lassen können. Die fleischliche Herrlichkeit markiert sowohl beim 
fleischgewordenen Wort des Prologs als auch beim verherrlichten Gekreuzigten der Passionsgeschichte das Ineinander von Gericht und Gnade. - Müsste sich dann aber nicht so etwas wie ein Neubeginn im Gemälde ankündigen?

Wenn das Weizenkorn nicht erstirbt...

Auch wenn man nicht weiss, dass Grünewald ebenfalls eine Auferstehungsszene gemalt hat, kann man, glaube ich, aus der Kreuzigung wahrnehmen, dass da noch etwas geschehen wird, dass die Geschichte noch nicht zu Ende ist. Dass aus diesem Sterben noch etwas anderes als blosses Sterben hervorgehen könnte. Auf vielfältige Weise kündigt es das Johannesevangelium antizipierend an, unter anderem im Bild des Weizenkorns, im Kapitel 12, in enger Verbindung mit einer Verherrlichungsaussage: «Die Stunde ist gekommen, dass der Sohn des Menschen verherrlicht wird. Wahrlich, wahrlich, ich sage euch: Wenn das Weizenkorn, das in die Erde fällt, nicht erstirbt, bleibt es allein; wenn es aber erstirbt, trägt es viel Frucht.» (Joh 12, 23f)

Wo taucht diese Botschaft, dass dieses Sterben lebendige Frucht tragen wird, in Grünewalds Gemälde auf? Vielleicht nur sehr indirekt: darin, dass neben dem etwas kitschigen Kelch des Lamms ein anderes Gefäss am Fuss des Kreuzes steht. Der Balsamtopf, aufbewahrt und bereit für die Einbalsamierung, verweist auf den kommenden Ostermorgen, wo er sich zwar gerade als unbrauchbar erweisen wird, weil der hier Sterbende nicht einzubalsamieren sein wird, weil er viel Frucht tragen wird, weil er ins Leben führt, und nicht in seinem Tod fixiert werden kann.

\section{Hermeneutischer Schluss}

$\mathrm{Ob}$ dies alles nun wirklich im Gemälde Grünewalds zu finden ist? Als hermeneutisch Geschulter muss ich damit rechnen, dass es ebenso sehr in mir als dem Betrachter präsent war. Doch nur dadurch kann es zu einer schöpferischen Interaktion kommen, nicht nur zwischen dem Bild und seinem Betrachter, sondern in allen dabei wirkenden Widerständigkeiten auch zwischen dem Bild, dem Betrachter und der in ihnen auf dem Spiel stehenden Sache, dem gewichtigen Gekreuzigten. Ihm gegenüber gilt am Schluss der Betrachtung für den Betrachter, was für Johannes den Täufer gilt: Illum oportet crescere, me autem minui.

— Dr. Pierre Bühler ist Professor für Systematische Theologie an der'Theologischen Fakultät Zürich. 